\title{
PROTECCIONISMO EN ECUADOR: CASO INDUSTRIA DE ENSAMBLAJE DE CELULARES
}

\section{PROTECTIONISM IN ECUADOR: CELL PHONE ASSEMBLY INDUSTRY CASE}

\author{
Angel Sotomayor Pazmiño, Ing. \\ Instituto Superior Tecnológico Guayaquil, Guayaquil, Ecuador. \\ angelfceb@gmail.com \\ Roberto Sandoval Valle, Econ. \\ Unidad Educativa Humberto Moreira Márquez, Ventanas, Ecuador. \\ rsandoval110393@gmail.com \\ José Cedeño Cabrera, Econ. \\ Instituto Ecuatoriano de Seguridad Social, Guayaquil, Ecuador. \\ joseandres4a@hotmail.com
}

\section{ARTÍCULO DE REFLEXIÓN}

Recibido: 16 de agosto de 2021

Aceptado: 11 de octubre de 2021

\section{RESUMEN}

Establecer políticas de protección o apertura para industrias ha sido un debate constante en el mainstream del pensamiento económico, sin embargo, el libre aperturismo se ha posicionado como artífice del desarrollo económico global a pesar de estudios económicos que presentan evidencia contraria. El fin de este trabajo no es seguir en el círculo vicioso de discutir si es mejor el proteccionismo o aperturismo, indudablemente tanto las estrategias de protección y liberalización han sido necesarias para el desarrollo por lo tanto las preguntas claves a cuestionar son: ¿A quién le funciona qué? y en un contexto en el que las economías del mundo buscan recuperarse después del embate sufrido a causa del Covid19 ¿En qué momento se deben aplicar políticas industriales de protección o liberalización? Por lo tanto, se presenta un trabajo descriptivo que genere un contraste entre lo que se dice y lo que ha sucedido respecto de los procesos de industrialización poniendo como sujeto de estudio a la industria de celulares en el país. Con esto se espera generar insumos sobre las opciones que tienen los países para recuperar e impulsar su desarrollo en un escenario post-covid.

Palabras claves: proteccionismo, liberalización, desarrollo, industrias, políticas.

\section{ABSTRACT}

Establishing protection or opening policies for industries has been a constant debate in the mainstream of economic thought, however, free openness has positioned itself as the architect of global economic development despite economic studies that present contrary evidence. The purpose of this paper is not to continue in the vicious circle of discussing whether 
protectionism or openness is better, undoubtedly both protection and liberalization strategies have been necessary for development, therefore the key questions to ask are: Who is it? works what? and in a context in which the world's economies seek to recover after the onslaught caused by Covid19, at what point should industrial protection or liberalization policies be applied? Therefore, a descriptive work is presented that creates a contrast between what is said and what has happened regarding the industrialization processes, putting the cell phone industry in the country as the subject of study. With this, it is expected to generate inputs on the options that countries have to recover and promote their development in a postcovid scenario.

Keywords: protectionism, liberalization, development, industries, policies

\section{INTRODUCCIÓN}

Crecimiento económico y Desarrollo son dos conceptos que hoy en día no pueden estar separados ni desentendidos el uno del otro, es uno de los tópicos más importantes para las naciones del mundo, ante esta situación siempre ha existido un acalorado debate sobre los procesos de desarrollo a lo largo de la historia con el surgimiento de diversas corrientes y escuelas económicas e ideológicas.

A pesar de la diversidad de argumentos contrarios y comunes entre la diversa comunidad de pensamiento político, social y económico acerca de los factores que han contribuido al desarrollo de los hoy llamados Países de Primer Mundo (PPM) si hay algo en lo que todas estas teorías concuerdan es que el descubrimiento, crecimiento, desarrollo e innovación de procesos de industrialización han sido un factor fundamental para que estos países se constituyeran en las potencias que son actualmente a pesar de todos los embates políticos y sociales como las guerras mundiales, naturales como tsunamis, terremotos y sanitarios de orden global como las Pandemias.

Los PPM como Estados Unidos, Francia, Holanda, Alemania, Inglaterra sufrieron muchos embates de los mencionados en el párrafo anterior antes y durante sus procesos de industrialización que si bien dificultaron sus objetivos de posicionamiento como potencias mundiales en tecnología, farmacéutica, medicina, comercio, etc se convirtieron justamente en la necesidad impulsora de sus logros económicos y sociales, por ejemplo después de la segunda guerra mundial muchas instituciones surgieron con la coalición de varios PPM consolidando así su liderazgo en las diversas áreas ya mencionadas.

Pero ¿qué sucedió con los países de América latina? ¿Por qué teniendo una magna cantidad de recursos no alcanzaron los mismos resultados que los PPM?, sobre esto ya se ha escrito bastante y existen muchas respuestas a estos enigmas del desarrollo; Por lo tanto, los objetivos que se plantean en este trabajo de investigación son los de generar un aporte al 
debate sobre qué tan exitoso ha sido el proteccionismo y la liberalización de mercados e industrias y en qué etapas de desarrollo en lugar de ahondar en el debate infinito sobre si es mejor proteger y liberalizar.

Como uno de nuestros objetivos secundarios o específicos se propone exponer a través del método descriptivo los intentos realizados por el Estado de transitar por el camino del desarrollo industrial, además analizar el caso de la industria de ensamble de teléfonos móviles entre 2012 y 2019 como proceso industrial emergente en el país, así mismo plantear evidenciar este caso como caso alternativo respecto a la teoría de que toda industria puede surgir, crecer y posicionarse debido a cierto grado de proteccionismo.

Con estos objetivos, recopilación de datos y material bibliográfico se espera tener como resultados una valoración de las políticas proteccionistas o de liberalización para reflexionar sobre los errores y aciertos de la política industrial en el Ecuador, para alcanzar este resultado se presenta un ejemplo concreto de la dinámica que tuvo el proceso de industrialización en el país con el ensamblaje de teléfonos móviles. Por otro lado, categorizar los elementos adicionales que se deben tener en cuenta para tener procesos de desarrollo industrial funcionales contrastando la realidad histórica del Ecuador con la de los PPM, y así también justificar la necesidad de una investigación posterior y más profunda sobre qué debería hacerse para que en el contexto ecuatoriano y a raíz de la Pandemia del COVID19 puedan surgir procesos de descubrimiento, crecimiento y desarrollo de nuevas industrias con características que les permitan hacer frente a las necesidades y oportunidades que presentan situaciones de embate natural como la que ha azotado a los seres humanos, a las empresas y a las naciones.

Uno de los elementos transversales considerados para el desarrollo de esta ponencia es el análisis de la formación de capital bruto y del modelo de industrialización vía sustitución de importaciones para generar un ejemplo alternativo al que los datos históricos sobre protección de industrias tratan puesto que a lo largo de la historia económica global muchos de los países hoy desarrollados utilizaron prácticas proteccionistas para alcanzar varios de sus logros económicos, de esta manera se presenta un narrativa distinta a lo tradicional con un ejemplo real sobre proteccionismo e industria no con el fin de agitar el avispero pero sí con el objetivo de aportar con ideas que conviertan al debate sobre estas temáticas en un punto de convergencia de la diversidad de pensamiento.

La pandemia que afectó al mundo durante el último año ha llevado a los gobiernos a repensar el curso de sus políticas públicas, hemos visto como Organismos Multilaterales han abogado por la asistencia del Estado en mayor o menor medida en favor de los ciudadanos y el nuevo momento histórico presenta como necesidad la adaptabilidad de los procesos de 
crecimiento y desarrollo a escenarios en los que los asuntos públicos de salud y sanidad juegan un rol muy importante, por ello es que además de lo ya mencionado en esta introducción se analiza el proceso histórico de cómo los Países de primer mundo fueron transitando por la senda del desarrollo, cómo Ecuador en concreto manejó su política de industrialización y que lecciones nos dejan estas narrativas para hacer frente a los nuevos retos que la pandemia ha presentado en el contexto global.

\section{MATERIALES Y MÉTODOS}

La metodología aplicada en este trabajo de investigación es de carácter descriptivo puesto que a través de la recopilación de material bibliográfico documental se presenta en primer lugar un análisis del contexto histórico económico sobre el desarrollo industrial de los países hoy llamados "potencias" para comprender cómo en determinados momentos el proteccionismo favoreció la creación y posición de industrias emergentes y así mismo cómo en determinados momentos la liberalización fue necesaria para consolidar las industrias plenamente consolidadas.

El método deductivo es la base de esta ponencia ya que parte de premisas generales acerca de medidas proteccionistas para plantear un caso específico como es los efectos de aquellas premisas a la industria de teléfonos móviles.

Los materiales a usados son documentos electrónicos, libros, artículos científicos, revistas virtuales, documentación y datos de organismos institucionales.

Ya establecidos los parámetros que constituyen el pilar de la investigación es necesario partir del breve análisis histórico del desarrollo de países como Estados Unidos (EU), Inglaterra, Alemania, Francia, Bélgica cuya realidad demuestra que contrario al libre aperturismo que ponderan hoy como arquitecto de su desarrollo fue justamente el uso de políticas de protección lo que los consolidó como Países Desarrollados y que una vez afianzados fue el libre aperturismo lo que les ha permitido mantenerse como las potencias que son, como mencionamos en la introducción de este texto no es afán de los autores ahondar en qué es mejor, si protección o apertura, pues es claro que en determinados momentos históricos el uso de ambas han sido beneficiosa y necesaria. (Rodrik, 2011)

Por ejemplo, Estados Unidos en 1820 implementó tasas arancelarias promedio de entre el 35 y 35\% sobre importación de productos manufacturados, así mismo Inglaterra por su parte tuvo tasas arancelarias promedio de entre el 45 y 55\%, Alemania de entre el 8 y $12 \%$, Dinamarca de entre el 25 y $35 \%$, todo esto en etapas tempranas del desarrollo de estos países que hoy son potencias mundiales. (Chang, 2003) 
Estas tasas arancelarias fueron disminuyendo a medida que estas naciones se consolidaban en industrias emergentes, por otro lado, el éxito alcanzado por dichos países no se debe exclusivamente a medidas de protección comercial; El espionaje tecnológico, la restricción de emigración de trabajadores mejor cualificados, la imposición de barreras comercial y tratados desiguales a colonias y países pequeños, la inversión en educación como en investigación y desarrollo ayudaron a consolidar el liderazgo comercial, científico, industrial y fue entonces que una vez consolidados como tales pudieron aplicar medidas de aperturismo que les garantizaron su permanencia en el globo económico e incluso político.

Las medidas proteccionistas al comercio pueden definirse como barreras arancelarias (BA) y las de protección a industrias como barreras no arancelarias (BNA), sin embargo, tanto las BA como las BNA están siempre relacionadas entre sí puesto que cuando se protegen industrias emergentes con el fin de que puedan desarrollarse se aplican barreras a la importación de productos manufacturados es decir restricción a las importaciones. En cuanto a las barreras arancelarias podemos mencionar a 3 principales elementos que son el ad valorem, arancel específico y mixto. (Betancourt, 2014)

Respecto a las barreras no arancelarias podemos mencionar la determinación de precios, las medidas compensatorias, la exigencia de un porcentaje de contenido mínimo o adicional de determinada mercancía, cuotas de importación, licencias, medidas cambiarias y demás estrategias específicas con relación a los intereses comerciales de cada nación. (Baena, 2018)

Es importante aclarar que estas medidas han ido evolucionando a través de la historia, en los primeros años de industrialización de los PPM el espionaje tecnológico, la captación de trabajadores mejor cualificados de otros países, las restricciones a las colonias, los altos aranceles eran algo no ético, pero prácticamente normal como por ejemplo Inglaterra que prohibía a Estados Unidos avanzar en la manufactura de bienes para consolidarse así mismo.

Una vía que ha tomado el Ecuador de manera histórica son las reformas arancelarias para sectores que por el contrario han tenido muy poca participación en la búsqueda de mejorar la oferta exportable, se intentó generar una transformación mediante el modelo de industrialización vía sustitución de importaciones que evidentemente no funcionó.

Durante el gobierno de la revolución ciudadana se generaron políticas de proteccionismo al comercio e industrias con el fin de transitar a un modelo de producción de mercancías con valor agregado. Si bien la protección a la industria nacional permitió una armonización de las políticas macroeconómicas a nivel intrarregional por un aumento de la oferta traducida en el incremento de la producción nacional no todas las áreas o sectores protegidos tuvieron los 
resultados esperados como la industria de ensamblaje de celulares que es el ejemplo planteado en esta investigación.

Aunque los procesos de industrialización toman décadas sino siglos como tiempo para consolidarse no basta con aplicar medidas comerciales de protección a todo, se necesita de políticas estratégicamente selectivas que tengan cohesión con instituciones que puedan encausar dichas políticas. A los países desarrollados les tomó no sólo la aplicación de medidas de protección estratégicas sino también de instituciones que dirigieran dichas políticas, es por eso que planteamos que el fondo Monetario internacional (FMI) por ejemplo es más bien el resultado que la causa del desarrollo económico de Estados Unidos. (Chang, 2003).

Los procesos de industrialización exitosa demuestran que hace falta más que sólo política pública enfocada al comercio para transformar la producción nacional, en primer lugar se debe contar con talento humano calificado para adaptarse a las dinámicas de nuevas industrias, infraestructura que permita que el personal humano pueda aplicarse, instituciones que fortalezcan los dichos procesos de industrialización, investigación constante y regulación estratégica de mercados, sobre estos elementos se abordarán conclusiones y recomendaciones. (Chang, 2003)

El Ecuador ha adoptó los lineamientos de la Comisión Económica para América Latina (CEPAL) conocida como la sustitución de importaciones. Esta teoría propugna la transformación de la matriz productiva con el fin de equilibrar el déficit de la balanza comercial. Este es uno de los elementos transversales que los autores consideran importante resumir. De acuerdo con CEPAL, el desarrollo de los países de América Latina está basado en aplicar medidas de política comercial, con el fin de eliminar gradualmente las importaciones de bienes, que con cierta inversión podrían ser fabricados en el país. Otro objetivo es no solo fomentar la industria nacional sino también mantener la dolarización que se encuentra vigente desde el año 2000, frente a una balanza comercial cuyo déficit sigue creciendo. (Vasquez \& Sánchez, 2018)

Aunque existe evidencia empírica que demuestra que la base del desarrollo de las industrias de varios países ha sido la aplicación de medidas de protección existen también casos muy concretos de que no se trata de protegerlo todo solo porque sí, debemos aprender de casos fallidos como sucedió con el Modelo de industrialización vía sustitución de importaciones, este es el caso de la industria de celulares que si bien es cierto empezó con un importante impulso a día de hoy aunque no ha desaparecido decayó y no se podido fortalecer o desarrollar este sector dejando como evidencia que no siempre el proteccionismo funciona llevándonos a optar por una estrategia de fortalecimiento de las exportaciones. 
Fue en el año 2012 que nuestro país se inicia en el sector del ensamblaje de teléfonos celulares y una de las primeras muestras de medidas de protección fueron las que se establecieron por medio del Comité de Comercio Exterior (COMEX) a través de la implementación de cupos para la importación de teléfonos celulares terminados (Super Intedencia de Control del Poder de Mercado, 2017).

Estas medidas fueron fortaleciéndose en 2015 con el establecimiento de aranceles ad valorem a la importación de componentes para ensamblaje del $15 \%$ cuando el porcentaje de producto ecuatoriano incorporado (PEI) fuera menor al 5\%, de $7,50 \%$ cuando el PEI fuera de $5 \%$ y así se estableció un umbral de arancel aplicable en función del PEI.

No sólo este arancel se aplicó, con la llegada de las salvaguardias se contemplaron otras tarifas que favorecieron en su inicio el sector de celulares móviles de gama baja que tuvieron una amplia acogida por su precio y su similitud con móviles de gama alta.

Es en concreto el análisis de la imposición de este arancel lo que se presenta como una de las causas para conocer los efectos y elementos que minaron el desarrollo de esta industria.

A continuación, se presentan gráficos sobre la dinámica del auge y caída de la industria de celulares contemplando análisis sobre la evolución del ensamblaje, el número de ensambladoras antes y después del arancel impuesto, analizar la formación de capital bruto con el fin de contrastar el crecimiento de las manufacturas en relación con el caso de los teléfonos móviles.

Tabla 1

Arancel ad valorem por producto ecuatoriano importado en ensambles de celulares.

\begin{tabular}{cc}
\hline \% de producto ecuatoriano incorporado & Arancel a pagar Ad valorem \\
\hline $\mathbf{2}$ & $15,00 \%$ \\
$\mathbf{5}$ & $7,50 \%$ \\
$\mathbf{6}$ & $6,60 \%$ \\
$\mathbf{7}$ & $5.70 \%$ \\
$\mathbf{8}$ & $4.80 \%$ \\
$\mathbf{9}$ & $3.90 \%$ \\
$\mathbf{1 0}$ o superior & $1,00 \%$ \\
\hline
\end{tabular}

Fuente: Resolución Nro. 051-2015 del Comité de Comercio Exterior.

Esta tabla de umbrales de arancel aplicado según porcentaje de producto ecuatoriano incorporado entró en vigencia el primero de enero del 2016, en el que se dicta un arancel máximo del $15 \%$ ad valorem a los ensambles de teléfono móvil que tengan menos del $5 \%$ de 
producto ecuatoriano insertado en los dispositivos y además durante el año 2016 se restringió el margen de importación de teléfonos móviles terminados desde el exterior.

Esto contrajo externalidades negativas no sólo en el ensamblaje pleno sino también en la importación de CKD.

El CKD es definido por el ministerio de comercio como partes, piezas o el conjunto de estas importadas ya sea por empresas y/o personas naturales con el fin de ensamble de productos y que están debidamente autorizadas en el exterior. (Ministerio de Producción, Comercio Exterior, Inversiones y Pesca, 2021).

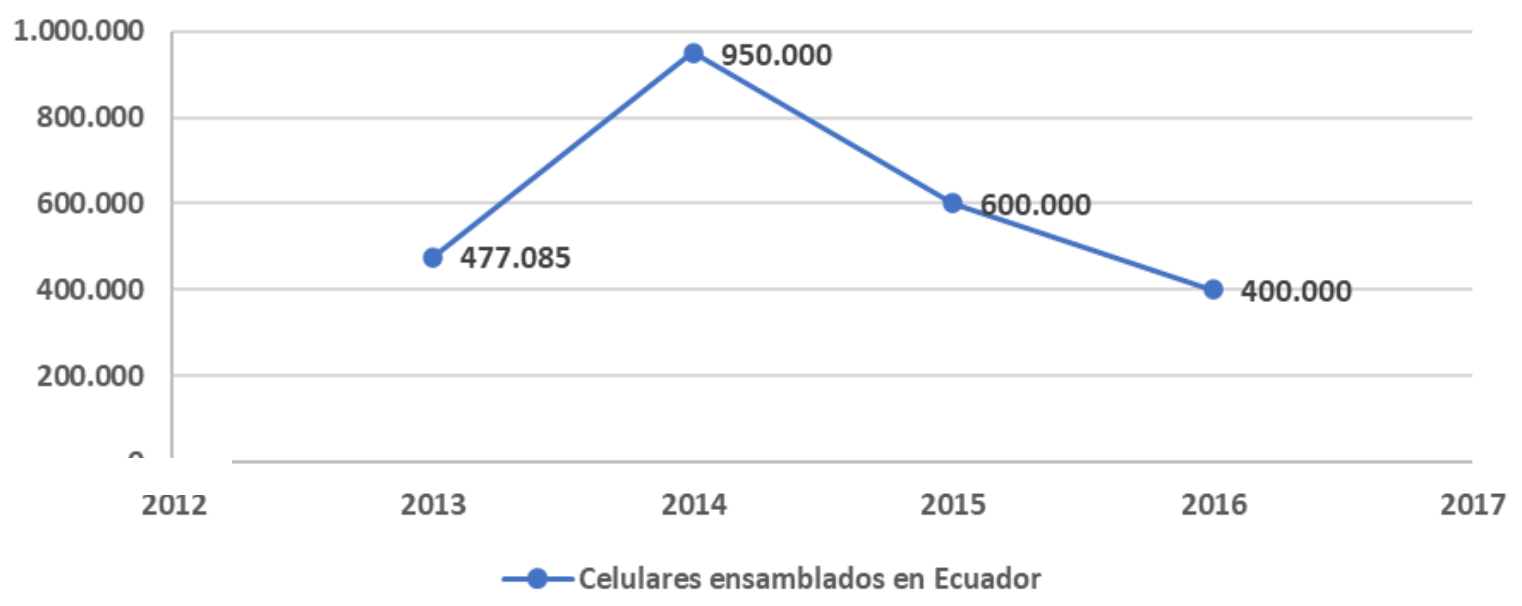

Gráfico 1. Evolución de ensamblaje de celulares en el Ecuador. Fuente: (Superintendencia de Control del Poder de Mercado, 2021)

Según datos del Ministerio de Industrias, para el 2013 se ensamblaron 477.085 teléfonos celulares en el país, tendencia que iba al alza ya que para el siguiente año se ensamblaron 950 000. En 2015 esta producción cayó a 600 mil unidades y con la resolución número 51 del Comex se estimó una baja de 400 mil unidades en 2016.

Es en 2016 cuándo se registran los valores más bajos respecto a la caída del ensamble de teléfonos móviles en el país, durante los años anteriores la industria tuvo un despegue significativo puesto aunque las salvaguardias ya habían restringido las importaciones de CKD y teléfonos móviles terminados no fueron tan agresivas para este sector como lo serían a partir de 2016 con una nueva medida de restricción de importaciones y además el arancel del $15 \%$ presentado en la tabla de la resolución 051 del Comité de Comercio Exterior, con esto precedente podemos ir apreciando que la aplicación del proteccionismo debe ser estratégico y evaluativo permanentemente porque en lugar de proteger un sector lo que conlleva es el ahogar y deprimir la industria, se debe entender que los procesos exitosos de industrialización tomaron siglos y esto entre fracasos y éxitos. 
A criterio de los autores, aunque el país necesita impulsar inminentemente nuevas industrias para transformar su matriz productiva sería ingenuo creer que estas se consolidarán en 10 o 20 años ya que siguiendo los ejemplos históricos de los países desarrollados un proceso de industrialización no sólo se compone de políticas de protección al comercio sino de infraestructura y de adaptación de las fuerzas productivas, esto es talento humano e investigación y ni hablar de los recursos económicos.

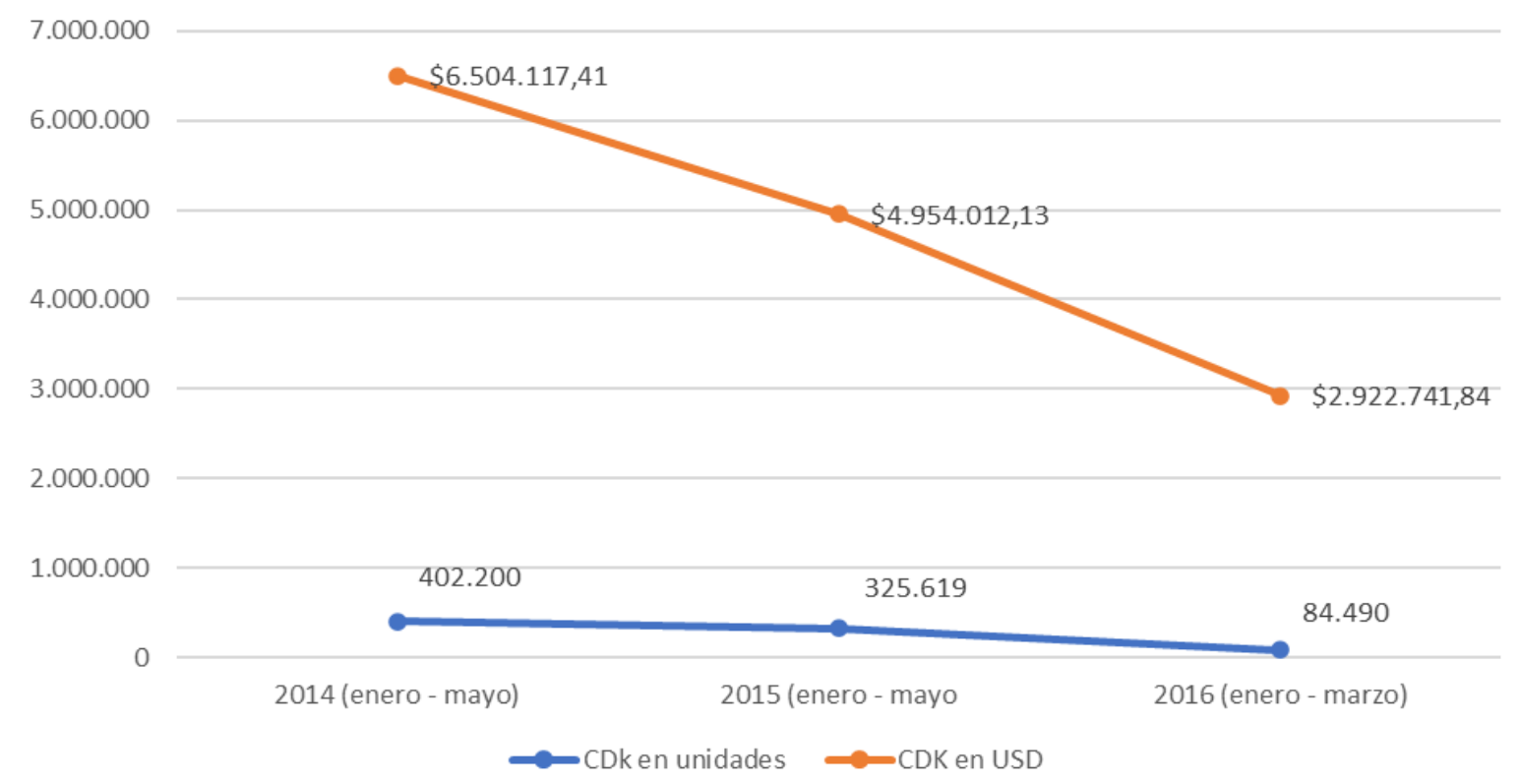

Gráfico 2. Importación de componentes para Ensamblaje de Celulares (CDK). Fuente: (Superintendencia de Control del Poder de Mercado, 2021)

Uno de los indicadores de la crisis que atravesó el sector ensamblador son las importaciones de componentes (CDK) para celulares. Entre enero y mayo de 2014 se importaron 402.200 unidades a un valor de $\$ 6$ '504.117,41; en el mismo periodo de 2015, 325.619 unidades por un total de $\$ 4$ '954.012,13; De enero a marzo5 de 2016, el total de unidades importadas cayó a 84.490 y el monto a \$2'922.741,84.

El CDK es uno de los insumos principales para el ensamblaje de teléfonos móviles, el reducir la importación de estos para sustituirlos por producto nacional es un acto de buena fe y además un acto necesario para transitar a un mayor porcentaje de Mano de Obra Ecuatoriana y Materiales Originarios en Ecuador (MOE) y por ende a tener una industria nacional de celulares consolidada pero querer hacerlo de manera tan brusca no traerá buenos resultados, un factor elemental que puede fortalecer el argumento y la realidad de la depresión de la industria en general fue el terremoto del año 2016 en el que se aumentó el IVA del $12 \%$ al $14 \%$ encareciendo diversos productos relacionados con este sector, al disminuir la importación de CKD en lugar de incrementarse el MOE en el ensamblaje lo que sucedió fue que cayeron los ensambles. 


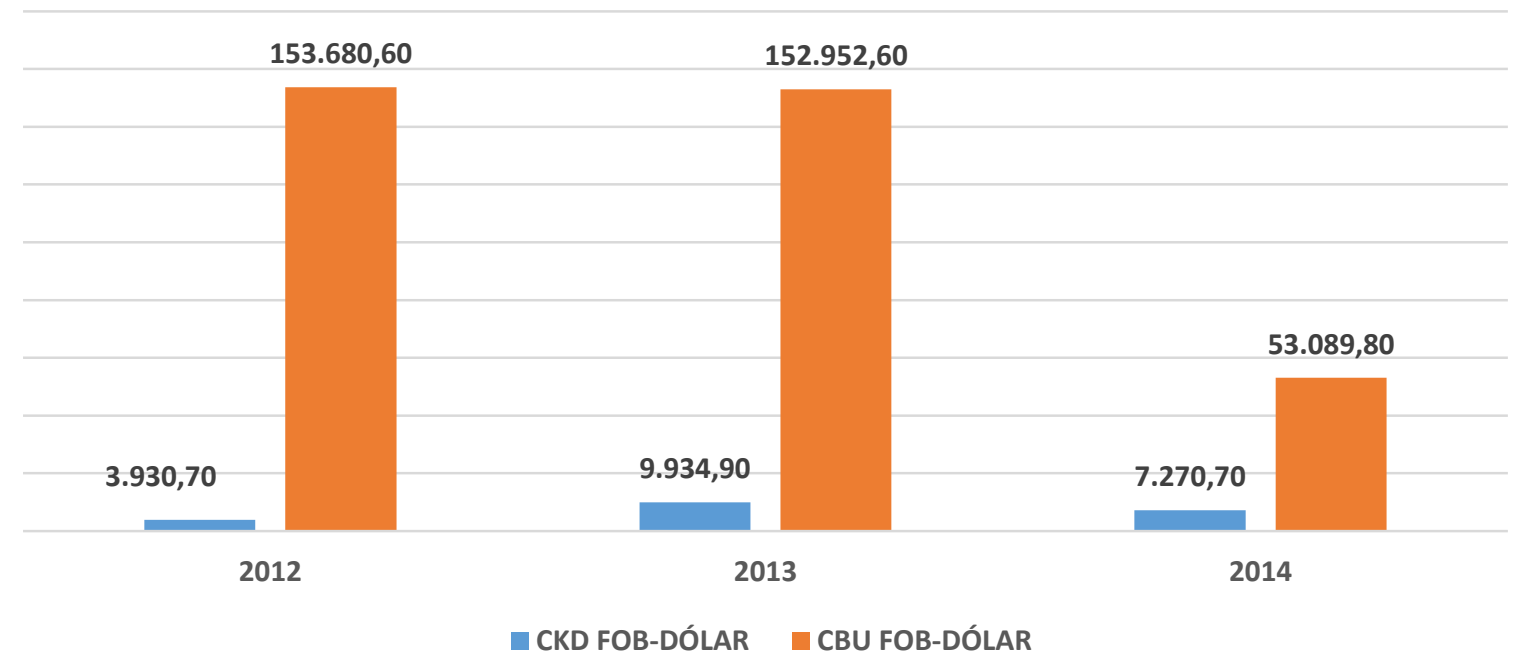

Gráfico 3. Participación de CKD vs. CBU en la importación de teléfonos celulares 2012 a 2014. Fuente: (Superintendencia de Control del Poder de Mercado, 2021)

Aunque la debacle de este sector se evidencia con mayor énfasis a partir del año 2016, existen elementos adicionales que jugaron un rol importante para la depresión de la industria del ensamblaje. En la Resolución № 14-263, emitida por el MIPRO en junio del 2014 se tenía como propósito incorporar la mayor parte de componentes nacionales en el proceso de ensamblaje, lo que debía llevar a un mayor encadenamiento con otras industrias locales proveedoras de baterías, cables, tarjetas electrónicas, etc.

En el gráfico 3 podemos ver que el monto en dólares de importación de teléfonos terminados fue mucho mayor al de CKD deprimiendo así la industria del ensamblaje en lugar de fortalecer, así mismo en lugar de generar un robustecimiento de industrias relacionadas a este sector lo que sucedió es que su participación en la industria disminuyó.

En la industria del Ecuador, el sector de telecomunicaciones se considera estratégico por su alto potencial tecnológico, este sector que se ha desarrollado rápidamente por sus usos y nuevas aplicaciones contiene inmersos elementos muchos más complejos que tan sólo las manufacturas y ensamblaje para ser más exactos. Además, crece por la necesidad del usuario de permanecer siempre intercomunicado. De acuerdo al Suplemento del Registro Oficial No. 725 y en base a datos de la SUPERTEL (actual ARCOTEL), las líneas de celulares llegaron a los 16 millones en abril del 2012. De esta cifra, el 18\% de las líneas cambian a nuevos celulares cada año.

Las compras de equipos celulares provenientes del exterior se incrementaron; por lo que el Comité de Comercio Exterior (COMEX) resolvió restringir cuantitativamente la importación y restringir totalmente la importación de los mismos a través de Correos del Ecuador, 
mensajería acelerada o Courier. La medida tuvo vigencia hasta el 31 de diciembre de 2014 y se prorrogó, posteriormente, hasta diciembre del 2015, con sus respectivas reformas. (Vasquez \& Sánchez, 2018).

Además de los recursos económicos, la infraestructura, el talento humano, las políticas comerciales de protección y las variables externas como el terremoto hay un factor adicional elemental que debido a la ausencia histórica y actual del mismo no se pudo consolidar como un sector fuerte el del ensamblaje de celulares y es el desarrollo de software, cada año sino es menos los celulares ensamblados debían hacer uso de actualizaciones de software provenientes de grandes marcas como Apple, Samsung, Huawei y demás que no permitieron un desarrollo integral de la industria en el país puesto que nuestra dependencia tecnológico en cuanto a software sigue siendo muy amplia y la brecha entre lo que hemos desarrollado y lo que podamos desarrollar sigue siendo grande.

Una vez más y como puntualizamos previamente sobre el desarrollo exitoso de modelos industriales, en un mundo en el que la Pandemia ha golpeado fuertemente a los países la gestión de los gobiernos debe contemplar programas integrales que contemplen formación de talento humano en sectores realmente estratégicos ya que no podemos seguir incursionando en ensayos de prueba error sobre industrias que nos llevan por delante siglos de desarrollo, por supuesto que se puede despegar pero las probabilidades son mínimas frente a grandes competidores con una fuerte participación de mercado.

No cabe duda que fomentar e impulsar industrias generará externalidades positivas al país como el aumento de la formación de capital bruto, pero no necesariamente todas las industrias hiper protegidas darán resultados, por lo menos no en el corto plazo refiriéndonos a esto como 10 ○ 20 años. (Stiglitz \& Greenwald, "La creación de una sociedad del aprendizaje", 2014)

Para evidenciar este punto se presentan datos sobre la formación de capital bruto en el Ecuador del 2012 hasta el 2019 como ampliación concreta del periodo de estudio para contrastación de la dinámica de esta investigación estos periodos representan el despegue y caída de la industria de celulares. 


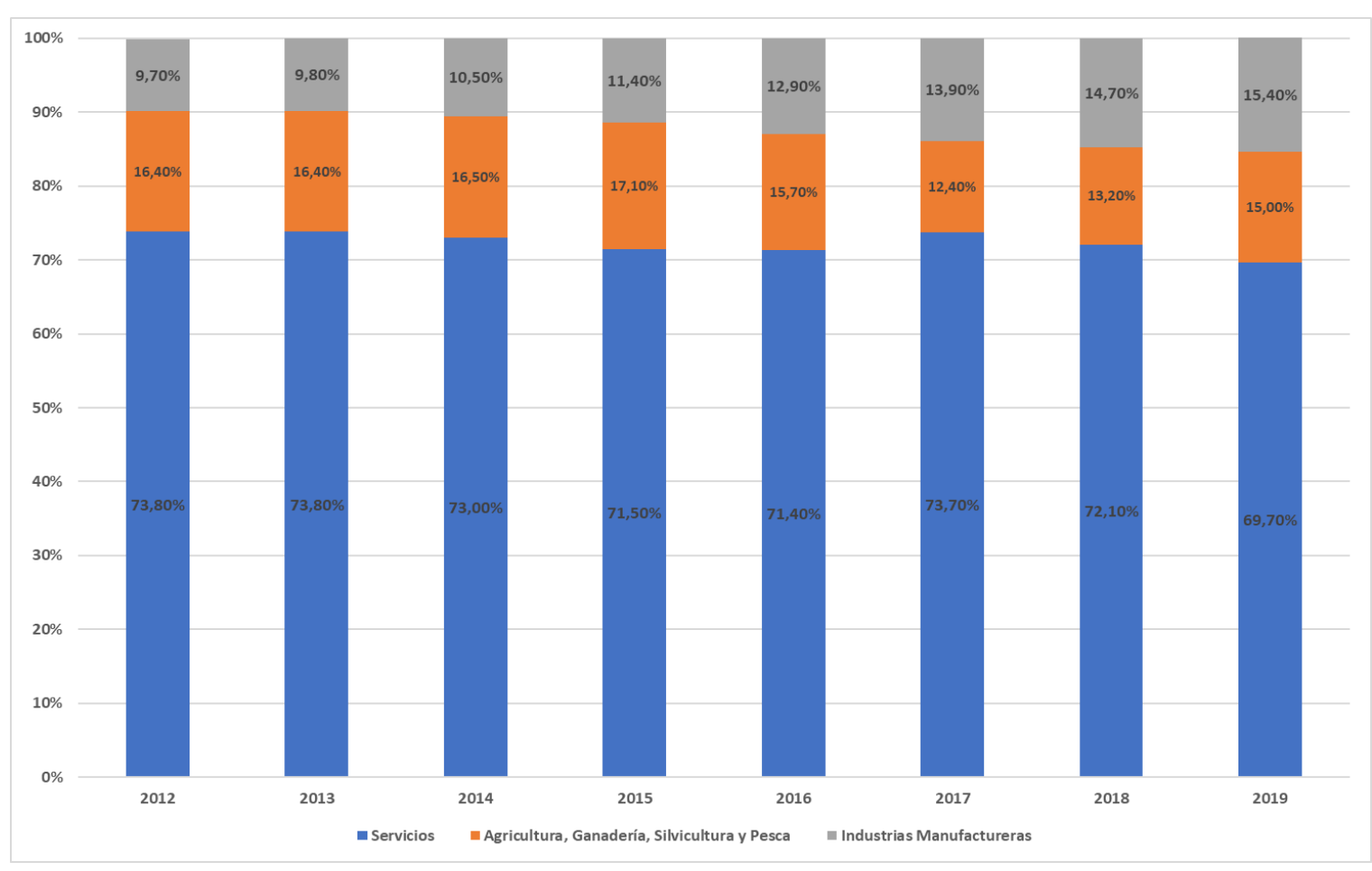

Gráfico 4. Formación Bruta de Capital Fijo Por industria - estructura porcentual 2017 - 2019.

Fuente: (Banco Central del Ecuador, 2021)

Para el año 2016 se contemplaron 20 empresas con debido registro para el ensamblaje de celulares, sin embargo, de las 20 empresas registradas en la Asociación de Ensambladores de Electrónicos y Eléctricos del Ecuador, 10 se encontraban activas hasta diciembre de 2016, 9 cerraron sus líneas de producción de ensamblaje de celulares y una de ellas contemplaba terminar sus operaciones. (Super Intedencia de Control del Poder de Mercado, 2017).

Aunque parezca simplista atribuir el éxito o fracaso de una seria de políticas comerciales por el número de ensambladores de celulares en Ecuador antes, durante y después de que las medidas de protección se tornarán fuertes para este sector sí refleja en gran medida los resultados que tuvo en nuestro país para esta industria.

\section{Perspectivas para el desarrollo industrial post pandemia.}

La pandemia ha demostrado que ni aún los países desarrollados pudieron contrarrestar los impactos del COVID-19, esto presenta desafíos comunes para el desarrollo, pero ¿Cuál es el camino que deben transitar las naciones en vías de desarrollo?, sin lugar a dudas es primero la recuperación en salud de los ciudadanos con un proceso ordenado, transparente y equitativo de vacunación, luego la salud de la economía. 
Lo primordial para generar un escenario de recuperación económica es generar un superávit por lo menos de la balanza comercial, si este camino toma las vías del proteccionismo o liberalización dependerá de cada nación. La situación del Ecuador respecto a su balanza comercial ha sido similar durante casi toda su vida republicana, pero desde que las medidas de protección comercial del presidente Correa se establecieron en el país la dinámica fue variante.

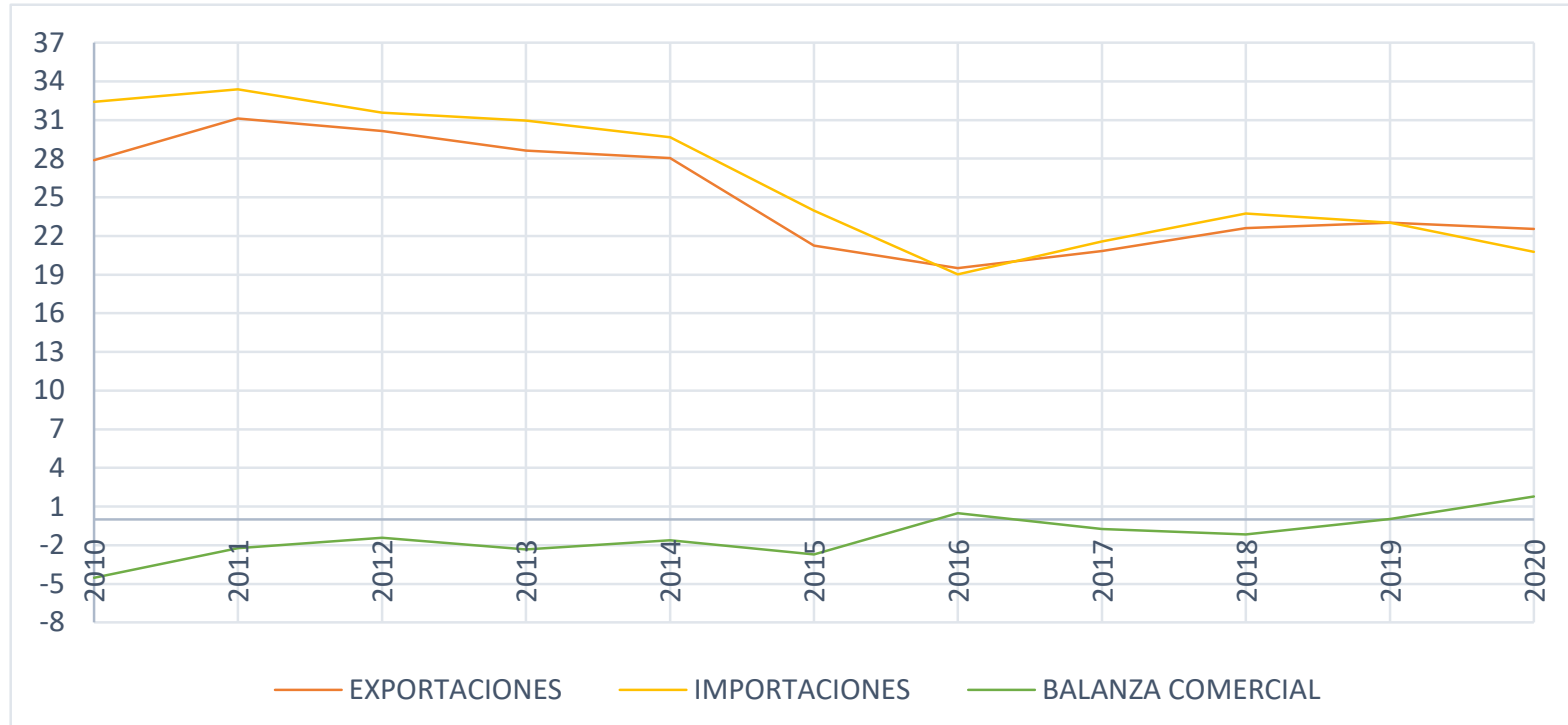

Gráfico 5. Balanza Comercial de Ecuador en millones de dólares del 2010 a 2020. Fuente: (Banco Central del Ecuador, 2021)

Ya que las exportaciones suponen una de las principales fuentes de dólares para economías que no mantienen una política monetaria la recuperación de la balanza comercial es imperante. En este contexto, la imposición de impuestos, como el Impuesto a la Salida de Divisas (ISD) y los aranceles suponen proteger la producción nacional y la fuga de moneda.

En este escenario post pandemia los países del mundo están optando por medidas de protección a sus economías, el caso de Ecuador fue el de las barreras arancelarias que actualmente están siendo disminuidas con la eliminación del ISD a las transacciones y envíos de líneas aéreas, además de la eliminación del arancel a bienes de capital. Según los autores estas medidas pueden ser beneficiosas, pero en el mediano plazo.

Respecto a esto, el escenario económico interno del país se mejoraría con un incremento de la demanda agregada, sin embargo, el escenario externo responde no a una dinámica de demanda sino de oferta. Puede ser dicotómico y es un reto para el Gobierno actual descifrar la correcta aplicación de las medidas de liberalización y protección para subsanar la economía dentro y fuera de nuestras fronteras. 
El virus que azotó el mundo presenta desafíos comunes para el desarrollo de los países, ante esto se debe reaccionar con líneas de cooperación más que de competencia en el corto plazo por lo menos hasta estabilizar la economía mundial, sin embargo, es necesario puntualizar que los impactos económicos que dejó el COVID-19 se profundizaron debido a problemas que siempre han estado presentes en materia social como la escasa preocupación de los gobiernos por la inversión en salud pública y sanidad, y como no también en educación, investigación y desarrollo sobre todo en los países de América latina que han sido los más golpeados por falta de sistema de salud preventivos y reactivos, escasa o paupérrima infraestructura médica, ínfima investigación científica sobre este tipo de externalidades negativas.

La pandemia ha llevado a replantear las metas y métodos de desarrollo, y si hablamos del horizonte post pandemia sobre desarrollo industrial Ecuador debe encontrar su ventaja comparativa y convertirla en su ventaja competitiva potenciando su talento humano en el descubrimiento y desarrollo de la industria bio-tecnológica, bio-farmacéutica en las que dicho mercado aún es relativamente joven y además en las que fenómenos como el COVID-19 generan un necesidad inminente de innovación en este sector.

Ecuador es uno de los países más bio-diversos del planeta y por lo tanto debe aprovechar su riqueza de manera equitativa pero sobretodo sustentable y sostenible, a criterio de los autores el futuro del desarrollo industrial post-pandemia para nuestro país es la "Bio-industria", por supuesto que identificar otros sectores de desarrollo industrial es una propuesta necesaria como la transformación de nuestros bienes primarios en productos de valor agregado pero esto tomaría más tiempo en posicionarse frente a productos que abarrotan el mercado mundial y puesto que la recuperación, fortalecimiento y desarrollo de nuestra economía no puede esperar más hay que apostarle a lo que nos puede tomar menos recursos y mejores resultados en menor tiempo, puede parecer idealista y es que para llevar a cabo este cometido hace falta inversión, mucha inversión en salud, educación, investigación e infraestructura.

\section{CONCLUSIONES}

El Ecuador al igual que los países vecinos vive un escenario complicado común, en el que el primer paso debe ser la recuperación económica, esta recuperación debe contemplar un papel activo del Estado como lo están haciendo las naciones más poderosas con incentivos a emprendimientos y asistencia social para los más pobres, los más afectados. 
El desarrollo industrial a partir de la nueva normalidad debe contemplar la adaptación de las cadenas de valor a externalidades negativas como las que presentó la pandemia, esto es una tarea imperativa puesto que los problemas de medidas sanitarias y fito sanitarias les han generado obstáculos a los productos ecuatorianos en los mercados internacionales, por lo tanto, el futuro de las cadenas de valor post pandemia debe ser reestructurado en base a las necesidades de esta "nueva normalidad".

La digitalización es otro elemento que los gobiernos de América latina deben contemplar en sus planes de desarrollo post-covid, el alto grado de contagio del nuevo virus acentuó la necesidad de migrar a estructuras comerciales digitales y para Ecuador desarrollar industrias de software ayudará a disminuir la dependencia tecnológica de las grandes potencias, el mercado digital es joven y Ecuador pueden posicionarse en el largo plazo.

Los procesos de desarrollo industrial requieren grandes esfuerzos económicos, y así mismo la Pandemia ocasionó grandes deudas para países en vías de desarrollo, no sólo deuda económica sino también social, ambos aspectos han afectado las finanzas públicas y es necesario subsanar y cumplir detectando adecuadamente las prioridades para poder poner en pie nuevas industrias, se insiste en que debe ser primero la salud del ser humano y luego o a la par la salud de la economía.

Nuestro país debe contemplar un modelo distinto al modelo ISI aplicado hace ya varios años para reemplazarlo por un modelo selectivo de exportaciones que contemplen una vez más la adaptación de las cadenas de valor a las necesidades que el COVID-19 ha presentado.

La transformación de bienes primarios a productos con valor agregado siempre ha sido una necesidad imperativa y aunque pueda sonar trillado, no podemos seguir vendiendo cacao para comprar chocolate, la inversión del Estado en proyectos estratégicos de desarrollo debe ser incesante pero también debe contemplar una suerte de alianzas público privadas que tengan como bandera las mejores prácticas empresariales.

\section{REFERENCIAS BIBLIOGRÁFICAS}

Baena, J. (2018). "Barreras arancelarias y no arancelarias como restricciones al comercio internacional". Revista Venezolana de Gerencia.

Banco Central del Ecuador (BCE). (2021). Formación Bruta de Capital Fijo.

Betancourt, B. (2014). Análisis Sectorial y Competitividad. Bogotá: ECOEBoberg-Fazlic, N., Lampe, M., Pedersen, M., \& Sharp, P. (2021). www.scopus.com. Obtenido de www.scopus.com: $\quad$ https://www.scopus.com/record/display.uri?eid=2-s2.085108001029\&origin=resultslist\&sort=plf- 
$\mathrm{f} \& \mathrm{src}=\mathrm{s} \& \mathrm{nlo}=\& \mathrm{nlr}=\& \mathrm{nl}=\& \mathrm{sid}=8 \mathrm{fdcf} 18 \mathrm{adc} 6071195 \mathrm{fb} 2195 \mathrm{ffe} 6 \mathrm{~d} 8 \mathrm{e} 6 \mathrm{a} \& \mathrm{sot}=\mathrm{b} \& \mathrm{sdt}=\mathrm{cl} \& \mathrm{cl}$ uster=scosubjabbr\%2c\%22SOCI\%22\%2ct\%2c\%22ECON\%22\%2ct\%2c\%22BUSI\%2 $2 \% 2 \mathrm{ct} \& \mathrm{sl}=28 \& \mathrm{~s}=$ TITLE-ABS-

Chang, H. (2003). "Kicking Away the Ladder".

Déniz, J., De León, N., \& Palazuelos, A. (2011). "Nuevas Estrategias Económicas en América Latina".

Forero C, \& Jaramilo, S. (2019). repository.javeriana.edu.co. Obtenido de repository.javeriana.edu.co:

https://repository.javeriana.edu.co/bitstream/handle/10554/45328/TRABAJO\%20DE \%20GRADO\%20CATALINA\%20FORERO\%20Y\%20SILVANA\%20JARAMILLO.pdf? sequence $=1$ \&isAllowed $=y$

Ministerio de Producción, Comercio Exterior, Inversiones y Pesca. (2021). https://www.gob.ec/mpceip. Obtenido de https://www.gob.ec/mpceip: https://www.gob.ec/tramites/buscar?search_api_fulltext=CKD

Oldekop, J. H. (2020). "COVID-19 and the case for global development". World Development. Rodrik, D. (2011). "una economía, muchas recetas".

Stiglitz, J. (2020). "Capitalismo Progresista".

Stiglitz, J., \& Greenwald, B. (2014). "La creación de una sociedad del aprendizaje".

Super Intedencia de Control del Poder de Mercado. (2017). www.scpm.gob.ec. Obtenido de www.scpm.gob.ec: https://www.scpm.gob.ec/sitio/versiones-publicas-de-estudios-demercado/

Vasquez, J., \& Sánchez, M. (2018). "Política de restricción a las importaciones de equipos celulares en el Ecuador y sus efectos en el desarrollo económico nacional". Economía y Negocios UTE. 